\title{
Meeting Student Needs: Integrating Spanish Heritage Language Learners into the Second Language Classroom
}

Clara Burgo

Loyola University Chicago, cburgo@luc.edu

Follow this and additional works at: https://ecommons.luc.edu/modernlang_facpubs

Part of the Modern Languages Commons, Modern Literature Commons, and the Spanish Linguistics Commons

\section{Recommended Citation}

Burgo, Clara. Meeting Student Needs: Integrating Spanish Heritage Language Learners into the Second Language Classroom. Hispania, 100.5, : 45-50, 2017. Retrieved from Loyola eCommons, Modern Languages and Literatures: Faculty Publications and Other Works,

This Article is brought to you for free and open access by the Faculty Publications and Other Works by Department at Loyola eCommons. It has been accepted for inclusion in Modern Languages and Literatures: Faculty Publications and Other Works by an authorized administrator of Loyola eCommons. For more information, please contact ecommons@luc.edu.

\section{(c) $(1)(9)$}

This work is licensed under a Creative Commons Attribution-NonCommercial-No Derivative Works 4.0 International License.

(C) AATSP 2017 


\title{
Hispania
}

\section{OPEN ACCESS}

Meeting Student Needs:

Integrating Spanish Heritage Language Learners into the Second Language Classroom

\author{
Clara Burgo \\ Loyola University Chicago
}

RESPONSES

Learning for All: Addressing Issues of Access and Participation in Mixed Classes

\author{
María M. Carreira \\ California State University, Long Beach
}

Community Engagement Pedagogy:

A Tool to Empower Heritage Language and Second Language Integration

Vanessa Marie Fernández

San José State University

Lucía Osa-Melero

Duquesne University

Hispania 100.5 (2017): 45-54

Hispania Open Access files are licensed under a

Creative Commons Attribution-NonCommercial-NoDerivatives 4.0 International License.

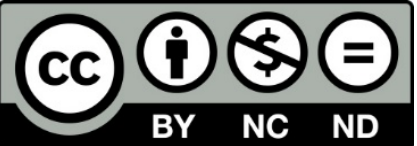




\title{
Meeting Student Needs: Integrating Spanish Heritage Language Learners into the Second Language Classroom
}

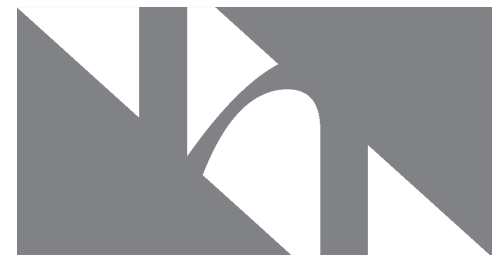

Clara Burgo Loyola University Chicago

\begin{abstract}
Despite the increase of Spanish heritage language (HL) courses in response to the linguistic needs of HL learners, these courses often combine this student population with advanced second language (L2) learners. This common scenario presents a challenge to many instructors who lack the training to negotiate intercultural and linguistic issues in the classroom so that all students can benefit. This essay presents key intercultural concerns (e.g., embarrassment and intimidation) and suggests strategies for instructors. Twenty-first-century students will work in collaborative contexts, so they must learn how to benefit from their classmates' strengths and work on their weaknesses through peer interaction and teamwork.
\end{abstract}

Keywords: intercultural issues/cuestiones interculturales, linguistic issues/cuestiones lingüísticas, literacy skills/habilidades de alfabetización, mixed learners/estudiantes mixtos, peer interaction/interacción de pares

\section{Introduction}

$\mathrm{D}$ ue to the growth of the Spanish-speaking population in the United States, many institutions have created specific courses for Spanish heritage language (HL) learners, who need a separate track due to their linguistic background (Bowles and Montrul 2014). These courses usually focus on literacy skills since many HL learners lack formal instruction in Spanish despite their early acquisition of the language in a naturalistic setting. Language educators generally concur with regard to the need for a separate track for HL learners at the lower-level language courses (Beaudrie and Ducar 2005; Draper and Hicks 2000). Less than half of US colleges and universities, however, offer a separate track (Beaudrie 2012). Even when institutions offer a separate track, HL learners are still regularly grouped together with second language (L2) learners in advanced-level content courses (Henshaw and Bowles 2015). This situation presents a challenge for many instructors who are not trained in how to deal with mixed learner (L2 and HL) needs in the same classroom to maximize the learning experience of all students. This essay reviews student opinions on this learning scenario, presents the main challenges for instructors addressing these views, and suggests key strategies for successfully guiding groups of mixed learners.

\section{Background}

Many institutions have created Spanish HL courses to address the linguistic needs of these learners, especially in areas with an increasing Spanish-speaking population. The rationale behind these courses is based upon both linguistic and affective factors (Colombi and Alarcón 1997; Potowski 2002; Valdés, Fishman, Chávez, and Pérez 2006). Furthermore, these courses are typically taught by trained instructors and focus on transferring HL learners' literacy skills 
from English and extending linguistic repertoires. Despite these recent trends, many HL learners remain in Spanish courses designed for L2 learners who possess minimal cultural and linguistic backgrounds in Spanish (Brecht and Ingold 1998; Valdés 1995). Moreover, in these mixed learner classrooms, instructors are usually trained to teach only L2 learners. Even if they have knowledge of HL instructional methodology, they are rarely familiar with approaches to mixed classes. As a consequence, these classes are problematic for many instructors. They also present serious concerns for HL learners, as many feel that instructors make false assumptions about their linguistic competence and, consequently, have higher expectations of them (Potowski 2002).

Research on mixed learner classrooms is scarce despite the prevalence of this scenario nationally (Beaudrie 2012; Henshaw and Bowles 2015). Bowles, Adams, and Toth (2014) conducted a study on L2-HL interactions in the mixed Spanish classroom to provide empirical evidence about whether the needs of both learner groups were met. Second language learners were able to fill gaps in their L2 when negotiating meaning with HL learners, so their learning process was facilitated without the errors that would inevitably occur between L2-L2 learners. This was one of the main benefits for L2 learners. Yet, there were also disadvantages: L2 learners felt more confident when interacting with students from a similar linguistic background. Perceiving HL learners as stronger speakers, L2 speakers reported feeling intimidated. This finding can be interpreted as an oral advantage for HL learners and a challenge for L2 learners. The only benefit that Bowles et al. (2014) find for HL learners in this situation is the opportunity to extend the use of their Spanish to the classroom setting. Thus, they propose using tasks that are mutually beneficial for both L2 and HL learners (e.g., oral and written tasks). Second language learners would benefit from HL learners in oral tasks and by obtaining direct access to the target culture (Katz 2003), whereas HL learners would benefit from L2 learners by improving their writing skills and learning metalinguistic grammatical terminology. Bowles (2011) suggests that engaging in a collaborative writing task could be beneficial for both groups of learners: L2 learners could help HL learners with diacritics and spelling (orthography) while HL learners could help L2 learners in amplifying their lexical repertoire. On the other hand, in a study by Blake and Zyzik (2003) on chat-based interactions, they found that HL learners assisted L2 learners more often than the inverse. Therefore, there were greater linguistic gains for L2 learners, but HL learners also experienced important benefits in affective factors, both linguistically and in terms of cultural self-confidence. In short, the presence of HL learners provides L2 learners with cultural gains, having access to native phonology and phonetics and being able to interact with native speakers. In turn, L2 learners can help HL learners with metalinguistic knowledge and orthographic rules (Edstrom 2007; Potowski 2002).

\section{Student Opinions on Mixed Learner Classrooms}

In a study on native, HL, and L2 learner experiences within mixed learner classrooms, Edstrom (2007) reports that L2 learners experienced an overall positive impact on their listening comprehension and oral skills. They also valued having access to fluent speech and diverse dialects and cultures. It was a true immersion experience for them since they had the opportunity to interact with native speakers in a conversational register, in contrast with the standard formal setting of the classroom. On an emotional level, they perceived respect and collaboration from their native and HL peers. Lacorte and Canabal (2003) argued that L2 learners did not feel intimidated by the presence of HL learners in the classroom. Nevertheless, in Edstrom (2007), the presence of HL learners affected the desire of some L2 learners to participate in class. From the perspective of HL learners, there was a consensus in reporting positive experiences with their L2 counterparts. They felt respected, appreciated, and were happy to help them. Additionally, they learned from L2 learner insights. In conclusion, all concurred that there was a pleasant atmosphere. Even though they agreed that it was better to have different tracks at lower levels, their answers varied for upper levels of Spanish, though most were satisfied with 
mixed classes. There were a few, however, who requested upper-level Spanish courses specifically for HL learners. This research suggests that our objective as instructors should be to maximize benefits for all learners.

Despite a general positive reaction, students highlighted feelings of intimidation or frustration as possible drawbacks to mixed courses. There was also an overall assumption by L2 learners that faculty expectations were higher when HL learners were present and that the pace of the course was faster. Likewise, HL learners sometimes felt that instructors had higher expectations of them (Potowski 2002). Nonetheless, in a recent survey by Bowles and Montrul (2014), it was reported that $75 \%$ of HL learners preferred taking language courses with L2 learners or did not have a preference.

Campanaro (2013) compared student opinions in mixed Spanish courses in Canada, where L2 instruction is more highly regarded than in the United States. Canada is a multicultural country where HLs are protected by the Canadian Multiculturalism Act of 1985. Consequently, differences between US and Canadian school contexts regarding the perception of the Spanish language and Spanish speakers might have an influence on student opinions on mixed classes. Campanaro's findings were positive and consistent with those of Edstrom (2007). Most L2 learners found that having HL learners in the same classroom was beneficial to their listening and oral skills, their insights, and their contributions, even though HL learner presence influenced their participation in class. Most of the HL learners were in favor of mixed classrooms and explained that they learned from their L2 counterparts. On an affective level, they felt appreciated and respected. Second language learners mentioned that they felt more comfortable working in groups since group work helped build their confidence. Both groups agreed that there were more benefits for L2 learners than HL learners regarding learning gains.

Research on the motivation for HL learners to take college language courses showed that they had a positive attitude towards the study of their language and culture but lacked confidence due to the low prestige of their Spanish dialect (Alarcón 2010; Beaudrie and Ducar 2005; Beaudrie, Ducar, and Relaño-Pastor 2009; Mikulski 2006). Thus, what HL learners expected from these courses was to improve their linguistic skills and acquire a standard dialect (Beaudrie and Ducar 2005).

\section{Challenges for Instructors in a Mixed Classroom}

After considering student opinions, we should identify challenges for instructors. As already mentioned, some students noticed that instructor expectations changed with HL learners in the classroom. Abdi (2011) conducted a study with HL learners in a high school classroom and found that one of the instructors was speaking more Spanish in class because of the presence of HL learners. This instructor admitted having considered HL learners to be native speakers, which might imply an extra burden for them considering that this could lead to creating false expectations among instructors about the students' linguistic competence by overlooking their actual linguistic status as active learners. Another potential problem could be excessively relying on HL learners for participation to the detriment of L2 students, who might not be valued for their own contributions and expertise.

One of the main challenges we face is the careful selection of classroom activities for HL learners. Though HL proficiency must be recognized, García and Blanco (2000) argue that HL learners should not be relegated to tutoring roles or be assigned as informants on culture or language, since these roles might deprive them of their own linguistic growth. Inevitably, we must differentiate instruction at times so that it does not neglect HL learners (Wilkinson 2010). Wilkinson (2010) conducted a survey on Spanish teachers in Utah with mixed classrooms, asking about special roles they designated to HL learners. The roles with highest percentages were those of native informants on language (64\%) and culture (59\%). In total, $76 \%$ of the instructors assigned HL learners to an informant role. Whether this is a good strategy might 
still be debatable, especially with regard to the possible negative impact on their own linguistic growth. Instead, García and Blanco (2000) suggest that small group instruction is crucial to meet the needs of both kinds of learners.

\section{Suggestions for Instructors to Overcome the Challenges Encountered in Mixed Classrooms: A Visionary Focus}

According to the US Census Bureau, there has been a $43 \%$ increase of Hispanics in the United States from 2000 to 2010 (Humes, Jones, and Ramírez 2011). Nevertheless, only 18\% of higher education institutions reported offering separate courses for HL learners in 2001 (Ingold, Rivers, Chavez Tesser, and Ashby 2002). Indeed, mixed classrooms have been the norm up to the present (Bowles and Montrul 2014; Lynch 2008). This trend suggests that mixed classrooms will continue to present challenges in the future. As educators, our visionary focus should be to overcome the challenges that diverse linguistic abilities might cause our students and make the mixed classroom the preferred pathway for the future through instructor training. This way, both L2 and HL learners can mutually benefit. We must provide sociolinguistic training for instructors, so that they can educate students on linguistic variation and help them become aware of and appreciate linguistic diversity, where no dialect is superior to another.

A visionary approach would seek out pair and small group activities that appeal to learner strengths while recognizing learner weaknesses (Henshaw and Bowles 2015). Instructors can reduce feelings of intimidation among L2 learners by encouraging them to establish meaningful relationships with diverse students; they should guide them to maximize the positive impact of this unique situation. Tutoring opportunities, group projects, and discussions can provide support for learners of all skill levels and backgrounds without dividing the class into L2 and HL learners (Edstrom 2007). Such a visionary approach normalizes the classroom environment as it reduces the gap between L2 and HL conversational performance levels. Consequently, L2 learner anxiety is reduced while increasing their tolerance and patience. This way, they can appreciate the immersion experiences created through opportunities to learn directly from HL learners.

Supplementary materials can also be used to adapt courses to meet all student needs, specifically with regard to the development of literacy skills for HL learners (Winke and Stafford 2002). Wilkinson (2010) likewise proposes textbook accommodations so that activities could be adapted for HL learners, focusing particularly on literacy skills. Campanaro (2013) further recommends tasks that encourage peer support and assessment strategies that reward the group, not only the individual. Second language and HL learners can mutually benefit from a mixed classroom setting. In content courses, HL learners can benefit from perspectives that L2 learners share about their own culture or heritage. Regarding language, HL learners can appreciate the control that many L2 learners have over grammar, use of diacritics, and metalinguistic knowledge. On the phonetic level, contrary to the general assumption that L2 learners have a disadvantage in pronunciation, they can actually help HL learners to become facilitators of the contrastive analysis between English and Spanish. For those who would like to teach Spanish, being aware of typical L2 pronunciation errors is very useful. Opportunities for teaching and learning should also be offered through peer work.

In Valdés, Fishman, Chávez, and Pérez (2008), high school Spanish teachers of HL learners argued that many practices commonly found in the advanced L2 classroom were also useful and necessary in the heritage classroom, including individual writing and revising, peer-editing, group research, and writing projects. Instructors could implement these practices in mixed classrooms. In fact, there are even textbooks written for both L2 and HL learners, such as Palabra abierta (Colombi, Pelletieri, and Rodríguez 2000), Avanzando: Gramática española y lectura (Salazar, Arias, and de la Vega 2012), and ¡Dímelo tú! (Rodríguez, Samaniego, Nogales, and Blommers 2005). 
Henshaw and Bowles (2015) suggest additional mutually beneficial activities for mixed classrooms: ethnographic interviews, dictogloss tasks, two-way crossword puzzles, translations, and phone tag activities. They also encourage class discussion topics, including stereotypes, social justice issues, bilingualism, relationships, study abroad opportunities, dialectal variation/ slang, film/art, work, and health. They recognize that choosing a teaching methodology is crucial for these students, highlighting three in particular: content-based instruction, project-based instruction, and language for special purposes. Through content-based instruction, students have access to authentic input. They can also acquire a sociolinguistic awareness of dialectal and register variation. By choosing project-based instruction (e.g., film series, translations, interviews, surveys, etc.), students serve an authentic purpose and develop an appreciation for collaboration. Finally, in a language for special purposes course (e.g., Business or Medical Spanish), both the content and purpose of the course are authentic.

\section{Conclusions}

Despite the growth of the Hispanic population across the country and the efforts made by colleges and universities to offer HL tracks for Spanish courses, most institutions still offer mixed classes, especially at an advanced level. Partially due to financial restrictions, it seems this trend will continue into the future. There are more benefits than drawbacks as a result of this learning situation. Nonetheless, instructors should work on overcoming the challenges this learning environment raises so that all learners can benefit. This could be achieved through collaborative group work, where students complement each other according to their strengths and weaknesses.

\section{WORKS CITED}

Abdi, Klara. (2011). “'She Really Only Speaks English': Positioning, Language Ideology, and Heritage Language Learners." Canadian Modern Language Review/La revue canadienne des langues vivantes 67.2: 161-90. Print.

Alarcón, Irma. (2010). "Advanced Heritage Learners of Spanish: A Sociolinguistic Profile for Pedagogical Purposes." Foreign Language Annals 43.2: 269-88. Print.

Beaudrie, Sara. (2012). "Research on University-based Spanish Heritage Language Programs in the United States: The Current State of Affairs." Spanish as a Heritage Language in the United States: State of the Field. Ed. Sara Beaudrie and Marta Fairclough. Washington, DC: Georgetown UP. 203-21. Print.

Beaudrie, Sara, and Cynthia Ducar. (2005). "Beginning Level University Heritage Programs: Creating a Space for All Heritage Language Learners.” Heritage Language Journal 3.1: 1-26. Web. 20 June 2015.

Beaudrie, Sara, Cynthia Ducar, and Ana María Relaño-Pastor. (2009). "Curricular Perspectives in the Heritage Language Context: Assessing Culture and Identity." Language, Culture and Curriculum 22.2: 157-74. Print.

Blake, Robert J., and Eve C. Zyzik. (2003). “Who's Helping Whom?: Learner/Heritage-Speakers' Networked Discussions in Spanish.” Applied Linguistics 24.4: 519-44. Print.

Bowles, Melissa. (2011). "Exploring the Role of Modality: L2-Heritage Learner Interactions in the Spanish Language Classroom.” Heritage Language Journal 8.1: 30-65. Web. 1 July 2015.

Bowles, Melissa A., and Silvina A. Montrul. (2014). "Heritage Spanish Speakers in University Language Courses: A Decade of Difference.” ADFL Bulletin 43.1: 112-22. Print.

Bowles, Melissa A., Rebecca J. Adams, and Paul D. Toth. (2014). "A Comparison of L2-L2 and L2-Heritage Learner Interactions in Spanish Language Classrooms.” Modern Language Journal 98.2: 497-517. Print.

Brecht, Richard D., and Catherine W. Ingold. (1998). “Tapping a National Resource: Heritage Languages in the United States.” ERIC Digest ED424791. ERIC Clearinghouse on Language and Linguistics. Washington DC. Web. 10 Oct. 2016.

Campanaro, Teresa G. (2013). "Spanish Heritage Speakers and Second Language Learners in Mixed Classrooms: Perceptions of Students and Instructors.” Diss. U of Alberta. Print.

Colombi, María Cecilia, and Francisco X. Alarcón. (1997). La enseñanza del español a hispanohablantes: Praxis y teoría. Boston: Houghton. Print. 
Colombi, María Cecilia, Jill L. Pellettieri, and María Isabel Rodríguez. (2000). Palabra abierta. New York: Houghton. Print.

Draper, James B., and June H. Hicks. (2000). “Where We've Been; What We've Learned.” Teaching Heritage Language Learners: Voices from the Classroom. Ed. John B. Webb and Barbara L. Miller. Yonkers: ACTFL. 15-35. Print.

Edstrom, Anne. (2007). “The Mixing of Non-Native, Heritage, and Native Speakers in Upper-Level Spanish Courses: A Sampling of Student Opinion.” Hispania 90.4: 755-68. Print.

García, Inés, and George Blanco. (2000). “Spanish for Native Speakers: K-12 Considerations.” Professional Development Series Handbook for Teachers K-16: Vol. 1. Spanish for Native Speakers (American Association of Teachers of Spanish and Portuguese). Fort Worth: Harcourt. 85-89. Print.

Henshaw, Florencia, and Melissa Bowles. (2015). "Meeting the Needs of L2 and HL Learners in Mixed Classes without Sending Mixed Messages.” Spanish as a Heritage Language Symposium. Texas Tech U, Lubbock, TX. Workshop.

Humes, Karen R., Nicholas A. Jones, and Roberto R. Ramírez. (2011). “Overview of Race and Hispanic Origin: 2010." US Census Bureau. Web. 24 Jan. 2014. PDF.

Ingold, Catherine W., William Rivers, Carmen Chavez Tesser, and Erica Ashby. (2002). "Report on the NFLC/AATSP Survey of Spanish Language Programs for Native Speakers." Hispania 85.2: 324-29. Print.

Katz, Stacey. (2003). "Near-native Speakers in the Foreign-language Classroom: The Case of Haitian Immigrant Students." The Sociolinguistics of Foreign-language Classroom: Contributions of the Native, the Near-native, and the Non-native Speaker. Ed. Carl Blyth. Boston: Heinle. 107-29. Print.

Lacorte, Manel, and Evelyn Canabal. (2003). "Interaction with Heritage Language Learners in Foreign Language Classrooms." The Sociolinguistics of Foreign-language Classrooms: Contributions of the Native, the Near-native, and the Non-native Speaker. Ed. Carl Blyth. Boston: Heinle. 107-29. Print.

Lynch, Andrew E. (2008). "The Linguistic Similarities of Spanish Heritage and Second Language Learners." Foreign Language Annals 41.2: 252-81. Print.

Mikulski, Ariana M. (2006). "Accent-uating Rules and Relationships: Motivations, Attitudes, and Goals in a Spanish for Native Speakers Class.” Foreign Language Annals 39.4: 660-82. Print.

Potowski, Kim. (2002). "Experiences of Spanish Heritage Speakers in University Foreign Language Courses and Implications for Teacher Training." ADFL Bulletin 33.3: 35-42. Print.

Rodríguez, Francisco, Fabián A. Samaniego, Francisco R. Nogales, and Thomas J. Blommers. (2005). ¡Dímelo Tú! Boston: Thomson. Print.

Salazar, Carmen, Rafael Arias, and Sara L. de la Vega. (2012). Avanzando: Gramática española y lectura. Hoboken: Wiley. Print.

Valdés, Guadalupe. (1995). “The Teaching of Minority Languages as Academic Subjects: Pedagogical and Theoretical Challenges.” Modern Language Journal 79: 299-328. Print.

Valdés, Guadalupe, Joshua A. Fishman, Rebecca Chávez, and William Pérez. (2006). Developing Minority Language Resources: The Case of Spanish in California. Clevedon, UK: Multilingual Matters. Print.

_ (2008). "Maintaining Spanish in the United States: Steps toward the Effective Practice of Heritage Language Re-Acquisition/Development." Hispania 91.1: 4-24. Print.

Wilkinson, Sara L. (2010). "A Survey of Utah Spanish Teachers Regarding the Instruction of Heritage Language Students of Spanish.” MA Thesis. Brigham Young U. Web. 11 Nov. 2014.

Winke, Paula, and Cathy Stafford. (2002). "Selecting Materials to Teach Spanish to Spanish Speakers." ERIC Digest ED464516. ERIC Clearinghouse on Language and Linguistics. Washington DC. Web. 27 June 2015. 